
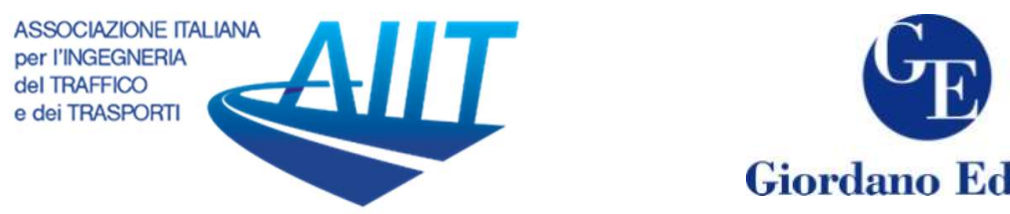

Giordano Editore

\title{
Statistical Analysis for Assessing the Built Environment Walkability of an Urban Area
}

\author{
Kavita Rani ${ }^{1}$, Amardeep Boora ${ }^{2 *}$, Manoranjan Parida ${ }^{3}$ \\ ${ }^{1}$ M. Tech student, Department of Civil Engineering, Indian Institute of Technology Roorkee, \\ India-247667, Email: kavita12aug@gmail.com \\ ${ }^{2}$ Assistant Professor, Department of Civil Engineering, Jaypee University of Information Technology \\ Waknaghat, India-173234, Email: amardeepboora9@gmail.com \\ ${ }^{3}$ Professor, Department of Civil Engineering, Indian Institute of Technology Roorkee, India-247667, \\ Email: mparida@gmail.com
}

\begin{abstract}
In the past era, in the transport planning process walkability was at the least priority as it was considered as a minor mode of transport. Though, it has its importance towards social life, economy, empirical quality and health. Consequently, the focus of the researchers across the world is now on walkability analysis. Therefore, to assess the walkability of an urban transport network in India, 15 different locations (i.e. institutional, educational, commercial, terminals and residential) were selected from three different cities. In the present study, different statistical techniques (i.e. factor analysis stepwise regression method) were used to identify a suitable number of data set based on their correlation analysis. Thereafter, land use-based and combined models were developed with the help of a questionnaire survey. Finally, different clustering analysis technique was used to assess the walkability thresholds which will make the job easier for sidewalk planners (i.e. in walkability analysis).
\end{abstract}

Keywords: Walkability, sidewalk, factor analysis, stepwise regression, clustering

\section{Introduction}

Walkability is a measure that examines how amenable a locality is to walk. In the past era, walkability was given the least priority by transport planners as it was considered a minor mode of transport. Though, walkability is directly addressed to the level of a built environment regarding how much it is friendly to the pedestrian to walk at that particular area or facility. As per Newman and Kenworthy (1999), before the major revolution in the transportation facilities in the nineteenth century, all of the streets were designed to support the pedestrian's walkability. Currently, walkability assessment becomes the point of interest of researchers across the world due to its importance towards social life, economy, empirical quality and health.

\footnotetext{
* Corresponding author: Amardeep Boora (amardeepboora9@gmail.com)
} 
Researchers define walkability in different ways. Some researchers defined walkability as an important concern in sustainable urban design (Shelton 2008), while Stanford (2003) identified walkability as an important concern in urban planning. Rattan et al. (2012) identified walkability as a measure of effectiveness and as transportation alternatives to cars. Therefore, walkability assessment is an important tool to evaluate the weaknesses of pedestrian networks of a particular community, become more physically active and healthy, and identify ways to increase economic and environmental feasibility.

\section{Benefits of Walkability}

It has been already supported by scientific evidence regarding the health benefits of walking and the changes in the built environment will help people in promoting their healthy lifestyle choice. Few of the benefits of walkability are discussed below.

\subsection{Economic Vibrance}

Walkable communities can become an avenue to increase economic vibrancy in several ways. As an example, peoples come out of their cars to interact with the surroundings, their business experiences which are the immediate benefits of a walkable community. Litman (2009) concluded that walkability improvements on a town's "Main Street" can surprise economic development. In another study, Litman (2004) analyzed for transit economic evaluation and proposed a model for evaluating non-motorized transportation and it was concluded that the government also can be benefited from sales tax revenue by providing a walkable environment or facilities in a particular area or locality without increasing the amount of land.

\subsection{Community Connection}

Walkability affects the liveliness of a particular community. Due to improvement in walkability facilities, people are encouraged to walk which makes a community more vital as people make more connections by engaging with each other. In another study (Litman 2003), it was concluded that encouraging people to engage with each other result in the increment in the neighborhood interaction and their unity i.e. community. Additionally, sharing of information with each other also helps to increase economic activity.

\subsection{Health improvement}

A walkable environment encourages people to walk which is beneficial for their health and ultimately reduces the health care cost. Earlier (Mccann 2005), it was concluded that $43 \%$ of people who walk at a safe place within 10 minutes meet the recommended daily activity level. Walking up to large extent for transport purposes decreases the risk of cardiovascular disease up to $31 \%$ as per the Toronto Public Health department. In another study, Hurby and $\mathrm{Hu}$ (2014) identified that physical activity has a significant role in fighting childhood obesity. 


\subsection{Environmental benefits}

In the twenty-first century, usage of the vehicle is increasing rapidly by which the quantity of harmful gases like $\mathrm{CO}_{2}$, methane and carbon monoxide etc. is increasing continuously and decreasing the quantity of oxygen $\left(\mathrm{O}_{2}\right)$. A safe walkable area within 1015 minutes from home encourages the people to travel on foot and leave their car at home, by doing so the rate of increase in the harmful gases gets curtailed. Several parameters and methodologies have been proposed by different researchers to evaluate the walkability of a particular neighborhood or locality. For example, Pushkarev and Zupan (1971) identified street and land-use context as an important factor affecting pedestrian patience or obligation for crowding in New York. In another study, Whyte (1980) identified many factors that influenced the performance of the pedestrians in New York City namely, the presence of seating, shade, water and junction points. In the latest study conducted by Mohan et al. (2015), it was observed that the fatality rate of pedestrians in India is higher in comparison to other modes of transport. These studies concluded that the Indian roads are particularly unsafe for pedestrians, cyclists and motorcyclists. The primary objective of the present study is to know about the pedestrians' perception of existing sidewalks facilities in their localities. Other main objectives of the present study are to identify the principal parameters which affect the walkability of pedestrians of an urban area and proposing walkability thresholds based on these factors.

\section{Background Studies}

Different studies were conducted across the world to examine the walkability of a particular area. Manaugh and El-Geneidy (2011) conducted a study to examine the correlation of walkability scores with household travel behavior using different methods namely, walkability index, walk opportunity index, pedshed method and walk score. Blecic et al. (2015) conducted a study to provide an urban design support system centered on pedestrian accessibility and walkability of places using Walkability Explorer technique. Glazier et al. (2014) examined the association between density and the destination by creating four Walkability Indexes which were namely, population density, residential density, availability of walkable destinations and street connectivity. In another study (Carr et al. 2010), the relationship between Walk Score and objective/subjective measures of the physical activity environment were analyzed using Environmental Systems Research Institute's (ESRI) ArcGIS suite. Based on the findings, it was recommended to use Walk Score as an alternative for estimating neighborhood density and access to facilities rather than as a global measure of neighborhood walkability. While Jun and Hur (2015) observed that the perceived walkability has a significant effect (i.e. in enhancing) on neighborhood social environment in comparison to physical walkability. Owen et al. (2007) conducted a study to examine the neighborhood walkability and the walking behavior of Australian adults. In the study, the geographic information system (GIS) method and different factors namely; dwelling density, street connectivity, land-use mix, and, net retail area were used to calculate the walkability index at the district level. Weinberger and Sweet (2012) concluded that the changes in walk mode share can be achieved after improving the walkability of the least walkable neighborhoods. Al-Hagla (2009) proposed a comprehensive approach to assess the walkability measures in Saifi Village of downtown Beirut. The micro-scale evaluation concluded that the walkability generators' performance has a profound negative effect on 
overall walkability performance compared with walkability catalysts performance. Yusuf and Wahed (2015) the local walkability index was identified as the easiest and cheaper technique to measure the walkability rating of an area and thus, it provides more genuine walkability ratings. Lo (2009) conducted a study to understand the walkability and the pedestrian's perception of the development of pedestrian space. Luadsakul and Ratanvaraha (2013) carried out a study to calculate the walkability index in Nakhon Ratchasima city of Thailand. The walkability index was found positively associated with land use and physical infrastructures of such area. Smith (2009) conducted a study to examine the importance of pedestrian perception in the analysis of walking behaviour and it was concluded that environmental measures should measure separately. Moudon et al. (2006) concluded that appropriate land use conditions and pedestrian facilities improvement programs in suburban areas can affect the mode choice and pedestrian travel significantly. Ariffin and Zahari (2013) identified different attributes which encourage the people to walk namely; good weather condition, less risk from crime, good sidewalk condition, less car on the street, wide sidewalk, enough lighting, amenities/activities along the way, good traffic signal/signage for pedestrian and slow movements of cars. Wilbur Smith Associates (2008) and Ministry of Urban Development (2008) claimed that a substantial number of trips in Indian cities are made by foot, but pedestrian facilities are neglected and are not given ample focus. Bhattacharyya and Mitra (2013) made an effort to make Siliguri into a walkable city by making peoples choose walking as their first choice for short trips and to make long-distance trips using a combination of walking and public transport instead of personal motorized vehicles. Besides this, several studies (de Oña et al. 2016, Bellizzi et al. 2019, Festa et al. 2019, Datey et al. 2012, Gehrke (2012), Southworth (2005), Gori et al. 2014, Guo (2009), Kelly et al. 2011 and Hung et al. 2010) were conducted across the world that focuses on the walkability analysis of an urban area.

\section{Methodology of The Study}

\subsection{Site Selection and Data collection}

The present study is focused on the evaluation of pedestrian's perception towards existing sidewalk facilities in an urban area. The study area for this research is taken as the Hisar and Chandigarh cities of Haryana state, Jaipur city of Rajasthan which is situated on level terrain in Northern India. To do the walkability analysis, 15 different locations (i.e. 5 from each city) were identified based on the pedestrian movements (i.e. institutional, educational, commercial, terminals and residential). A detailed discussion regarding the profile of each city has been made below.

\subsection{Profile of Hisar City}

Hisar city was originally called 'Hisar Firoza (also Hisar-e-Firoza). Hisar city is spread in an area of about 2180 hectares and it is the world's second-largest Harappa site after Mohenjo-Daro. The existing road design and infrastructure does not cater to the needs of pedestrians. The adequacy of footpath width is found to be $30 \%$, which is a very less amount. The main reason for the inadequacy of footpath width is the lack of space on the sides of the carriageway. Footpaths are either not available or poorly maintained which reduces the walk trips of Hisar. 


\subsection{Profile of Chandigarh City}

Chandigarh is a city and a Union Territory of India which serves as the capital of two states of India, namely Haryana and Punjab. Chandigarh was designed by Swiss-French architect Le Corbusier and counted as one of the early well-planned cities of India. According to the walkability index score developed by the Ministry of Urban Development of India (MOUD 2008) by assessing pedestrian infrastructures of 30 cities, an average score of 0.52 was obtained out of 1 and Chandigarh has got the highest of 0.82 .

\subsection{Profile of Jaipur City}

Jaipur is the capital of Rajasthan, the largest state of India. Jaipur City is famous for its extraordinary buildings and its vibrancy is effectively depicted by the color and also called by the name of "Pink City". Jaipur is one of the most popular tourist destinations in India. As per the latest report of Jaipur Development Authority (JDA) 2010, 51\% of the total road length is facilitated with sidewalks or foot-over bridges. Consequently, the required data was collected through a questionnaire survey (i.e. personal interview survey method). These study locations have different geometric conditions and different roadway characteristics, i.e. sidewalk width varying according to the land uses. Details of survey locations in Hisar, Chandigarh and Jaipur City have been tabulated in Table 1. It is to note that the pedestrian perception also gets varies as per the location, land use and many more factors are there which influence the perception of the pedestrian up to a great extent. In the present study, information like pedestrian perceptions and socio-economic characteristics of pedestrians were gathered by conducting a questionnaire survey. A total of 704 pedestrians participated in the questionnaire survey. Data collection was performed on weekdays only at each of the study sites from morning 8 a.m. to 6 p.m. except in institutional areas. In institutional areas, a questionnaire survey was conducted in the morning during $8 \mathrm{a} . \mathrm{m}$. to $10 \mathrm{a} . \mathrm{m}$. and in evening from 4 p.m. to $6 \mathrm{p} . \mathrm{m}$. as pedestrian flow was peak at these times. In the data cleaning process, 60 questionnaire forms were removed as these were found to be incomplete. While a total of 100 data samples were preserved for the model validation process. The questionnaire was divided into two sections. The first section included questions related to socio-demographic characteristics like age, gender, occupation, the reason for not walking and in the second section, respondents were asked to rate the sub-factors defined under main factors that enhance walkability like safety from traffic, safety from crime, pedestrian convenience, sidewalk infrastructure and accessibility. These variables were identified as independent variables, while another variable named pedestrian's perceived walkability, was identified as a dependent variable. The traffic safety scale evaluates whether pedestrians are safe on the street (i.e. marking for pedestrian crossing, pedestrian signals, traffic control devices, underpass or foot over the bridge for crossing etc.). Facilities provided for Personal security i.e. provision of lighting, closed-circuit television (CCTV) cameras, police patrolling, good visibility etc. assess the safety of pedestrians from being looted or get murdered by thieves. While comfort and convenience show how much pleasant the environment is (i.e. how they feel means angry or happy from the facilities provided to them e.g. cleanliness of sidewalk, street furniture, landscapes, public utility etc.). Pedestrians infrastructure describe the basic facilities provided to the pedestrians for walking (i.e. footpath width, height, continuity of footpath, encroachment etc.) and in the 
last, accessibility assesses the extent of easy access of the pedestrians to another area or destination (e.g. walkable distance to commercial area, to the terminal, institutional building etc.). Table 2 presents the factors and sub-factors which were taken into consideration for the present study. Responses of pedestrians regarding the importance and performance of existing sidewalks of Hisar, Jaipur and Chandigarh's pedestrians were compared. The comparison of the pedestrian's perception towards sidewalk condition was done based on a five-point Likert scale in which "one" exhibits the poor condition while "five" stands for the excellent condition of sidewalks. Initially, the importance rating was calculated by considering the pedestrian's perception towards different variables which reflects the sidewalk condition of that particular neighborhood as shown in Figure 1. It implies that pedestrians will prefer to walk if an improvement will be observed in these facilities. Based on the results, in Hisar and Jaipur city, more than $65 \%$ of pedestrians were found more concerned about the safety from traffic as the guard rails were not provided on the footpaths. Besides this, there were no crossing facilities like foot-over bridge and underpass for pedestrians except at terminal areas which make the road crossing more dangerous.

Safety from crime was another important parameter, which was followed by others like sidewalk infrastructure, pedestrian's convenience and accessibility as shown in Figure 1. The main reason for being a safety concern is the absence of CCTV cameras and the very low frequency of police patrolling. Besides this, pedestrians complained about the absence of other facilities like provision of benches, public utility and cleanliness etc. While in the case of Chandigarh city, safety from crime was identified as the major concern for the pedestrians during walking in the streets in the early morning and late nights (i.e. due to inadequate lighting facilities) as it got the highest importance rating of 3.82 as shown in Figure 1.

Table 1: Description of the Study Sites

\begin{tabular}{|c|c|c|c|}
\hline Study Site & Location & Category & Footpath Width (m) \\
\hline \multirow{5}{*}{ Hisar } & Bus Stand & Terminal & 1.8 \\
\hline & Red Square Market & Commercial & 1.8 \\
\hline & Govt. PG College & Institutional & 3 \\
\hline & Sector 15 & Residential & 2.26 \\
\hline & Town Park & Recreational & 1.81 \\
\hline \multirow{5}{*}{ Chandigarh } & Sect. 17 Bus Stand & Terminal & 1.9 \\
\hline & $\begin{array}{l}\text { Shastri Market Sect. } \\
\qquad 22\end{array}$ & Commercial & 3.5 \\
\hline & PEC University & Institutional & 2.2 \\
\hline & Sect. 21 & Residential & 1.95 \\
\hline & Rock Garden & Recreational & 1.91 \\
\hline \multirow{5}{*}{ Jaipur } & $\begin{array}{l}\text { Sindhi Camp Bus } \\
\text { Stand }\end{array}$ & Terminal & 1.83 \\
\hline & Chaura Rasta & Commercial & 1.8 \\
\hline & MNIT Jaipur & Institutional & 1.86 \\
\hline & G. Colony & Residential & 1.95 \\
\hline & Nehru Park & Recreational & 3 \\
\hline
\end{tabular}

However, on the major roads of Chandigarh city, lighting arrangements were found up to the mark. Safety from traffic was identified as the other main concern having importance rating of 3.74 as there was no available foot-over bridge and underpass for pedestrians 
crossing at any of the locations except the terminal area. Alternatively, pedestrians were also bothered about other parameters which were ordered as a convenience, sidewalk infrastructure and accessibility. Later, a comparison was also made for the weighted mean of the satisfactory ratings observed for each sub-criterion for all the study sites namely, Hisar, Chandigarh and Jaipur City. From the point of safety from traffic, traffic volume, the potential for vehicle conflict, traffic control devices and traffic speed facilities were found satisfactory as per pedestrian perception at all the study sites. In the case of personal security, provision of lighting, outdoor lighting and good visibility were found satisfactory, while in the case of pedestrian comfort and convenience, none of the facility was found up to the mark as observed in the field as well as from participant's point of view. However, people gave average importance to the pedestrian facilities related to the pedestrian infrastructure (PIS). Besides these, in case of accessibility, which had the least priority to pedestrians, pedestrian volume, walkable distance to commercial area, walkable distance to institutional building, walkable distance to mixed land uses and twoway movement of the pedestrian was performing satisfactorily. Based on the pedestrian's perception it was concluded that improvement in the facilities as discussed above can increase the walkability of these cities.

\section{Assessment of Walkability Thresholds}

An attempt was made to calibrate different walkability thresholds to make the process of walkability analysis easier for sidewalk planners in the field. For the same, different models namely, based on gender difference, land use based and a combined model were developed in the present study using different statistical techniques (i.e. factor analysis, stepwise regression analysis etc.). Firstly, 38 parameters were factor analyzed for each model (i.e. based on land use and combine model) with the help of principal component analysis with orthogonal varimax rotation to reduce the number of variables and to group all the variables having high correlation. In the primary phase of factor analysis, number of variables were removed which showed correlation less than 0.40 (Stevens 1992). It is to be noted that Kaiser Meyer Olkin (KMO) value ranges from 0 to 1 , the KMO value equal to or greater than 0.5 is recommended for a satisfactory (i.e. minimum criteria) factor analysis (Hidayat et al. 2011, Yong and Pearce 2013 and Williams and Brown 2012 and Hidayat et al. 2011). Besides this, Watkins (2018) mentioned that the KMO statistic (Kaiser 1974) was required to be above a minimum of 0.50 . Consequently, the suitability of factor analysis was evaluated with KMO which exhibits the overall sampling adequacy for land use based models were namely $0.611,0.60,0.654,0.790$ and 0.734 explaining $74.09 \%, 80.35 \%, 71.96 \%, 71.79 \%$ and $76.07 \%$ variance of the data set for commercial, recreational, educational, terminal and residential area respectively with an eigenvalue greater than 1. Total ten variables (i.e. pedestrian signal, guard Rail, CCTV cameras, abandoned building or lot, good visibility, street furniture, landscapes, Public utility functions, curb cut and encroachment) were removed in the factor analysis for the commercial land use model (suggested 9-factor solution) as shown in figure 2. A total four number of variables (another pedestrian access point, tactile flooring, footpath width and continuity) were removed during the factor analysis process for the recreational land use model suggesting a 10-factor solution. In the case of the educational land-use model, six variables (sidewalk maintenance, pedestrian signal, another pedestrian access point, public utility function, ramps and abandoned building or lot) were removed and a 9-factor solution was suggested. After removal of four numbers of variables i.e. pedestrian signal, 
guard rail, street furniture and continuity, 8-factor solutions were obtained for the terminal land-use model. While, residential land use model suggested a 7-factor solution after removing six variables (pedestrian signal, encroachment, obstruction, pedestrian volume, good visibility and cleanliness of sidewalk). In the case of the combined model, a KMO value of 0.785 was observed which explains $66.08 \%$ of the variance and suggested a 9factor solution. Both the models were showing appropriate KMO values which were greater than the required $\mathrm{KMO}$ (i.e. $\mathrm{KMO}>=0.5$ ) as shown in Table 2.

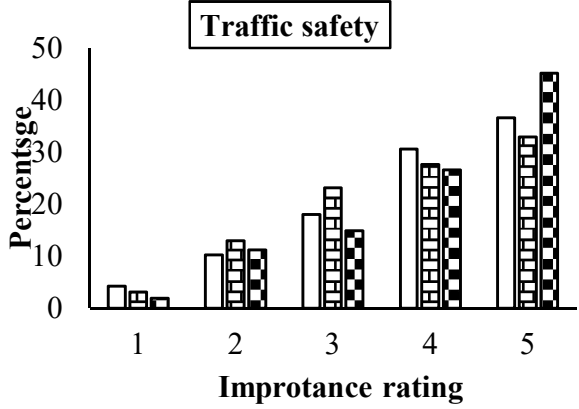

(a)

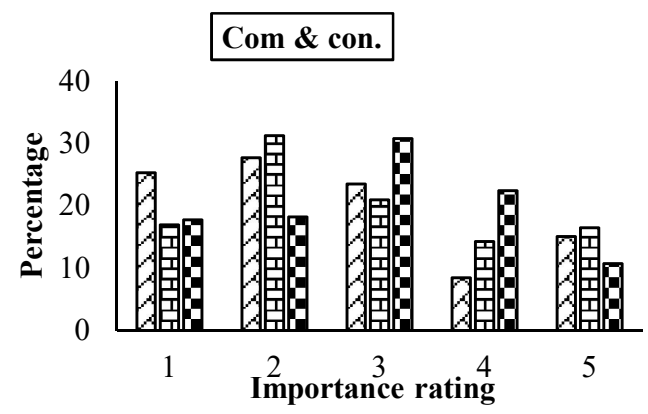

(c)

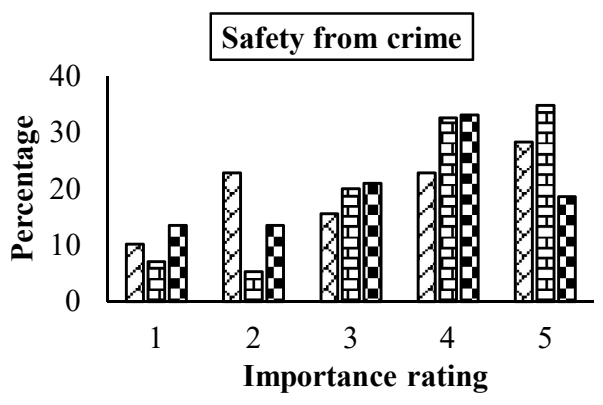

(b)

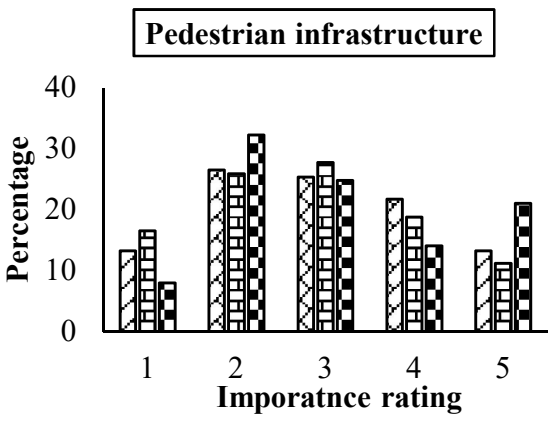

(d)

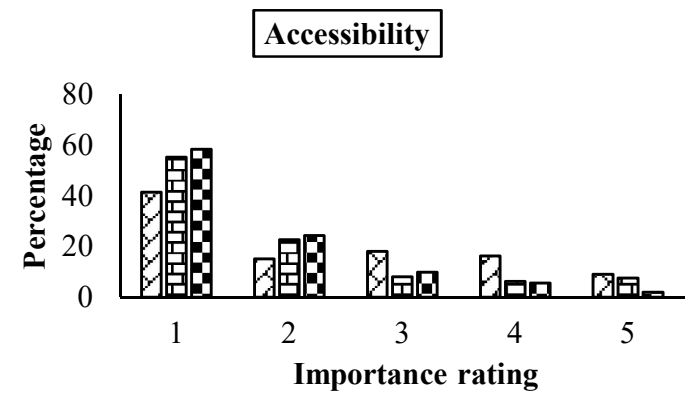

(e)

$\square$ Hisar City $\mathbf{9}$ Chandigarh City $\square$ Jaipur City

Figure 1: Importance rating observed across all the study sites 


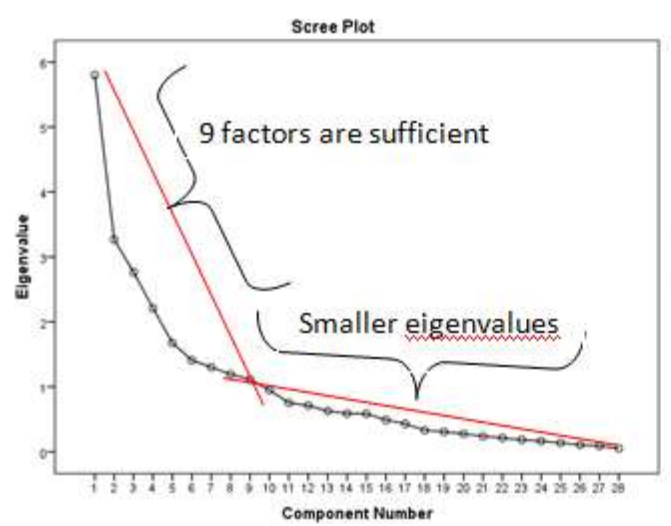

(a) Commercial land use

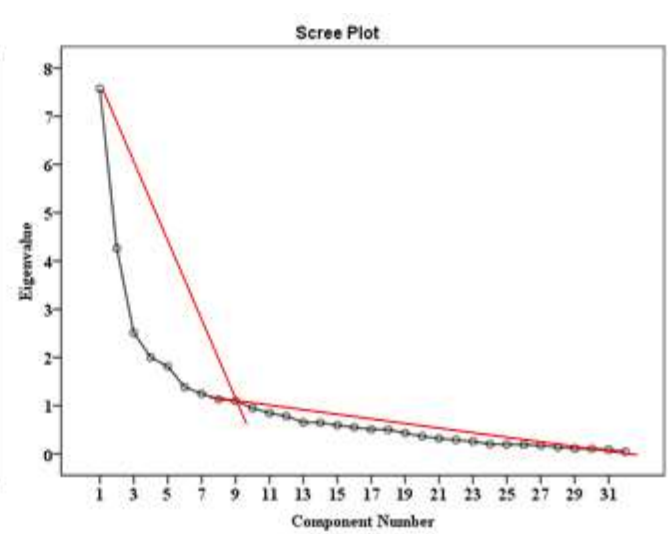

(b) Educational land use

Figure 2: Scree plot for factor analysis based on land use based model

Table 2: Summary of Factor Analysis

\begin{tabular}{|c|c|c|c|c|c|c|}
\hline \multirow[t]{2}{*}{$\begin{array}{l}\text { Analytic } \\
\text { Strategy }\end{array}$} & \multicolumn{5}{|c|}{ Land Use Based Model } & \multirow[t]{2}{*}{$\begin{array}{c}\text { Combined } \\
\text { Model }\end{array}$} \\
\hline & Commercial & Recreational & Educational & Terminal & Residential & \\
\hline $\begin{array}{c}\text { Cronbach's } \\
\text { Alpha } \\
\text { Kaiser }\end{array}$ & 0.734 & 0.728 & 0.837 & 0.799 & 0.785 & 0.80 \\
\hline $\begin{array}{l}\text { Measure of } \\
\text { Sampling } \\
\text { Adequacy } \\
\text { (KMO) }\end{array}$ & 0.61 & 0.60 & 0.65 & 0.79 & 0.60 & 0.79 \\
\hline $\begin{array}{c}\text { Bartlett test } \\
\text { of }\end{array}$ & 1265.38 & 2677.28 & 2086.92 & 2812.67 & 1679.99 & 4989.32 \\
\hline $\begin{array}{c}\text { sphericity } \\
\text { Chi-square } \\
\text { df }\end{array}$ & 378 & 561 & 496 & 561 & 528 & 435 \\
\hline $\begin{array}{c}\text { Significanc } \\
\mathrm{e}\end{array}$ & 0.000 & 0.000 & 0.000 & 0.000 & 0.000 & 0.000 \\
\hline
\end{tabular}

Bartlett test of sphericity also exhibited the overall significance of correlation matrix $<$ 0.000001. Besides this, Cronbach's Alpha test was performed to examine the reliability and internal consistency of the variables for all the study areas. It is to note that a Cronbach's Alpha coefficient value equal to or greater than 0.70 is acceptable (Choi et al. 2016). A factor analysis result for both models is tabulated in Table 2 below. Finally, a stepwise regression analysis based on a t-test was carried out to developed different models at a 95\% significance level. Stepwise regression systematically adds the most significant variable or removes the least significant variable during each step and by doing so the coefficients of the best set of the variables that define the suitable model will be finalized as the coefficients of regression analysis. Table 3 exhibits the result obtained from stepwise regression analysis for each type of model. All the parameters were found statistically significant at a $95 \%$ confidence level except the underlined value. After analyzing all the models, land use based models were found appropriate for the study. In a stepwise regression model, independent variables were selected automatically through step-by-step iteration. From Table 3, it can be observed that land used based models (i.e. for commercial, residential, recreational, terminal and educational) were found significant at $95 \%$ confidence level having a high $\mathrm{R}^{2}$ value in comparison to other models. 
European Transport $\backslash$ Trasporti Europei (2021) Issue 82, Paper n 1, ISSN 1825-3997

Table 3: Summary of Stepwise Regression Analysis

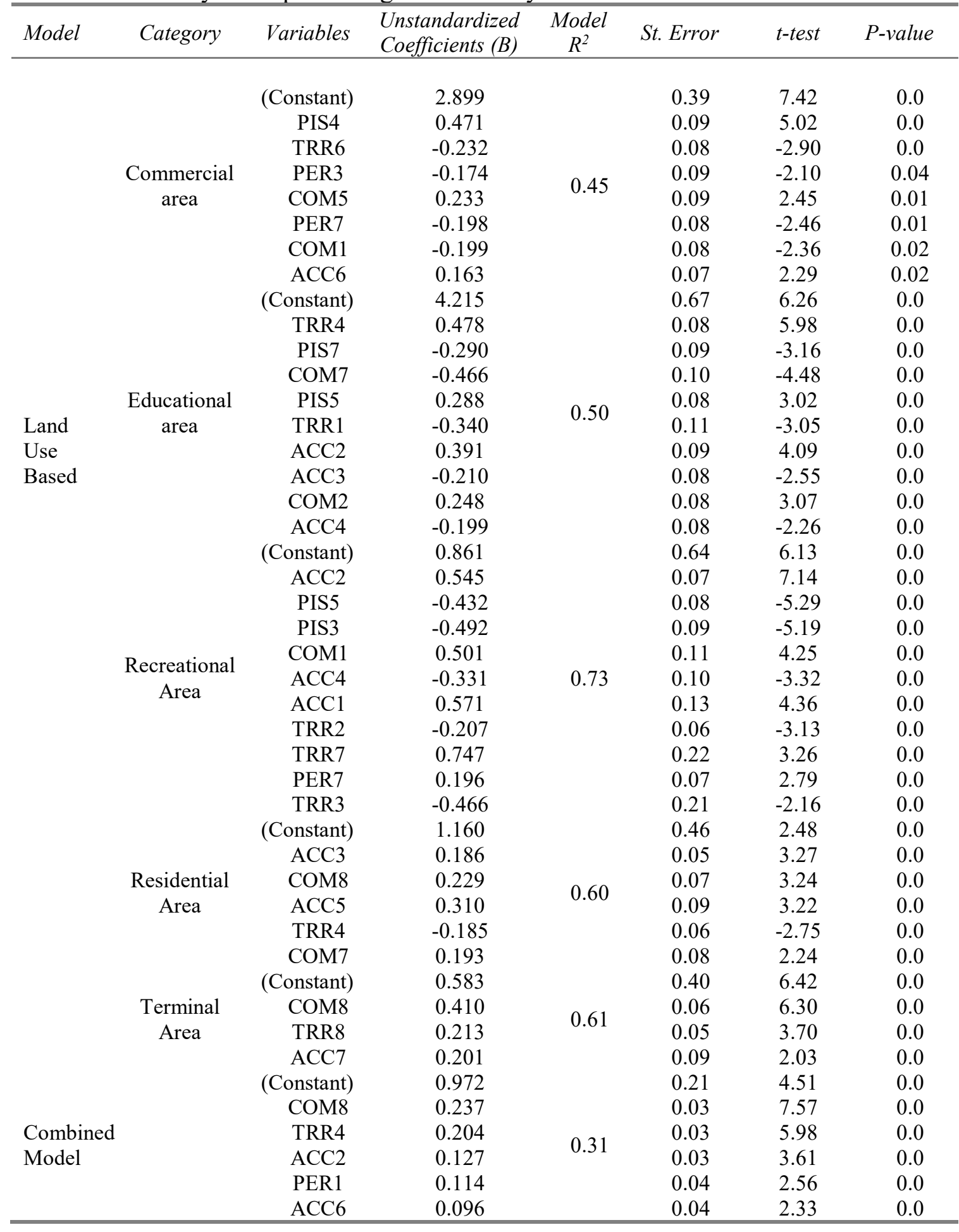

T-test results indicated that all independent variables are statistically significant. In the case of a model developed for commercial land use, COM5 (0.233) was identified as the most influencing followed by TRR6 (-0.232). The model developed for educational land use exhibited TRR4 $(0.478)$ as the most influencing variable followed by COM7 (-0.466). The recreational land use model identified TRR7 $(0.747)$ as the most influencing variable 
followed by ACC1 (0.571) and ACC2 (0.545). Besides these, ACC5 (0.310) and COM8 (0.410) were found the most influencing parameter for residential and terminal land-use based model respectively. To validate the models, a total of 100 unused data samples were used. Initially, the walkability score was calculated as per the pedestrian's perceptions are shown in Table 4. Later, ratings provided by participants were used in all the developed models. Table 4 is exhibiting the result obtained from the land-use based model. It is to be noted that the percent difference observed between perceived and predicted (i.e. using a model) walkability score were found to be less than 10 percent for all the land use type models which implies that the proposed models can be used for evaluating the walkability of an urban area. To provide a unique scale to evaluate the walkability of a particular area, the whole data set of land use based models were used to calibrate threshold ranges of walkability score.

As the classification of a data set into different groups is a classification related problem, the clustering analysis technique was used to assess different ranges. Clustering analysis is a technique used to divide different data set or objects into classes of similar data or objects (Kouser and Sunita 2013). Clustering analysis was carried out using the most popular distance matric named Squared Euclidean distance to develop different walkability score ranges considering all the study sites. Earlier, Jain et al. (1999) reviewed different clustering techniques and identified the clustering technique as a useful tool for the researcher of different disciplines. Murugesan and Moorthy (1998) used fuzzy clustering to examine the level of public transport service (LOPTS). It was concluded that the fuzzy approach can be used to assess the LOS of public transport. Therefore, data were clustered into five cluster groups using k-mean clustering techniques to calibrate the different walkability score thresholds. In this study, walkability score thresholds are provided to designate the worst condition (i.e. not walkable) to the best one (i.e. walkable paradise). The analysis was conducted in MATLAB and the number of iterations was set to 100 to obtain optimal boundaries. Consequently, the Silhouette plot was used to validate the distance selection criteria for clustering analysis which has been used in several studies (Rousseeuw 1987; Saha 2013 and Boora et al. 2017). The silhouette plot having a value of 0.70 was examined with the help of the universal thumb rule as shown in Table 5 which seemed reasonable.

Table 4: Walkability score obtained from pedestrians perception and land-use based models

\begin{tabular}{cccc}
\hline Model & $\begin{array}{c}\text { Perceived } \\
\text { Walkability Score }\end{array}$ & $\begin{array}{c}\text { Modeled Walkability } \\
\text { Score }\end{array}$ & \% Error \\
\hline Commercial land use & 3.0 & 3.2 & 6.6 \\
Educational land use & 3.2 & 3.4 & 6.25 \\
Recreational land use & 3.1 & 3.2 & 3.22 \\
Residential land use & 3.47 & 3.6 & 3.74 \\
Terminal land use & 3.1 & 3.4 & 9.6 \\
\hline
\end{tabular}

Table 5: Cluster validation criteria 


$$
\begin{gathered}
0.71-1.0 \\
0.51-0.70 \\
0.26-0.50 \\
<0.25
\end{gathered}
$$

$$
\text { A strong structure has been found }
$$

A reasonable structure has been found

Weak structure has been found

No substantial structure has been found

Finally, different thresholds were calibrated using clustering analysis as shown in Table 6. Earlier, MOUD (2008) also proposed different walkability score ranges in the range of 0 to 1 , where 0 exhibit poor walking conditions while 1 stand for good walkability. Consequently in the present study also, walkability score thresholds are proposed in a combined manner for all the selected study sites to keep a single scale to evaluate the walkability of different cities (based on the land-use model). A comparison was made between the walkability score value proposed for the Jaipur city in the MOUD report (0.64) and in the present study based on land use basis models (3.36). Based on the results, it was concluded that the proposed threshold ranges of walkability score can be used for the walkability assessment of an urban area.

Table 6. Proposed walkability thresholds obtained from partitional data clustering

\begin{tabular}{ccc}
\hline Ranges & Walkability Score & Interpretation of Walkability \\
\hline F & $\leq 1.19$ & Not Walkable \\
E & $>1.19 \leq 2.30$ & Poorly Walkable \\
D & $>2.30 \leq 2.97$ & Satisfactory \\
C & $>2.97 \leq 3.58$ & Average \\
B & $>3.58 \leq 4.24$ & Good Walkable \\
A & $>4.24$ & Very Good Walkable \\
\hline
\end{tabular}

\section{Conclusion and Future Scope}

Based on the observations made during the study, it was concluded that safety from traffic is the principal parameters in Hisar as the pedestrians were mostly concerned (more than $65 \%$ ) due to the absence of pedestrian signals, guard rails, foot-over bridge and many more. Besides this, safety from crime was found as the second important factor followed by pedestrian convenience, sidewalk infrastructure and accessibility. In the case of Jaipur, safety from traffic was identified as the principal parameters as found in the case of Hisar as participants gave it more importance in comparison to others. Besides this, safety from crime was found as the second important factor followed by sidewalk infrastructure, pedestrian's convenience and accessibility. Pedestrians of Chandigarh were found more concerned about safety from crime followed by safety from traffic, pedestrian's convenience, sidewalk infrastructure and accessibility.

It is to note that Adlakha et al. (2016) considered several parameters previously to evaluate the walkability of the neighborhood. However, no walkability threshold values were proposed to evaluate the walkability of the neighborhood. Besides this, Raparthi (2014) also proposed a theory of planned action, which can be incorporated by urban planners in the beginning stage of planning steps to address sprawl instead of using complicated political policies that will help in the economic development of a city. In the present study, land use based models were found most appropriate with high $\mathrm{R}^{2}$ value in 
comparison to others. After combining all the data samples of land use based models, different walkability score thresholds (i.e. from A to F) were proposed using clustering analysis by which a pedestrian or town planner can evaluate the walkability of an urban area very easily.

For the future scope, study can be extended further by developing age-based models as the perception will vary from age to age (i.e. child to senior citizen). The same study can be done in the hilly regions also (i.e. after including other factors). Other clustering techniques like fuzzy clustering, hierarchical clustering and many more can be used to assess different threshold values of walkability scores for different models.

\section{References}

Adlakha, D., Hipp J A \& Brownson, R C. (2016) "Adaptation and evaluation of the neighborhood environment walkability scale in India (NEWS-India)." Int. J. Environ. Res. Public Health, 13, pp. 401-412.

Ariffin, R N R \& Zahari, R K. (2013) "Perceptions of the urban walking environments." Procedia-Social and Behavioral Sciences 105, pp. 589-597.

Al-Hagla, K S. (2009) "Evaluating new urbanism's walkability performance: A comprehensive approach to assessment in Saifi Village, Beirut, Lebanon." Urban Design International 14(3), pp.139-151.

Bhattacharyya, D B \& Mitra, S. (2013) "Making Siliguri a walkable city." Procedia Social and Behavioral Sciences 96, pp. 2737 - 2744.

Boora A., Ghosh, I \& Chandra, S. (2017) "Assessment of Level of Service Measures for Two-Lane Intercity Highways under Heterogeneous Traffic Conditions." Canadian Journal of Civil Engineering 44, pp. 69-79.

Blecic, I., Cecchini, A \& Trunfio, G A. (2015) "Towards a design support system for urban walkability." Procedia Computer Science 51, pp. 2157-2167.

Census of India. (2011) "Haryana Provisional Population Tables." Director of Census Operations Haryana.

Choi, Y., Seo, M J \& Oh, S H. (2016) "Walkability analysis of Busan's urban residential zones." KSCE Journal of Civil Engineering 20(6), pp. 2535-2547.

Carr, L. J., Dunsiger, S I \& Marcus, B H. (2010) "Walk score ${ }^{\mathrm{TM}}$ as a global estimate of neighborhood walkability." American journal of preventive medicine 39(5), pp. 460463.

Glazier, R.H., Creatore, M. I., Weyman, J. T., Fazli, G., Matheson, F I., Gozdyra, P., Moineddin, R., Shriqui,V. K \& Booth G. L. (2014) "Density, destinations or both? A comparison of measures of walkability in relation to transportation behaviors, obesity and diabetes in Toronto, Canada." PLoS ONE, 9(1), pp. 85295.

Hruby, A \& Hu, F.B. (2014) "The epidemiology of obesity: a big picture."

Pharmacoeconomics 33, pp. 673-689.

Initiative, C A, \& Cities A. (2011) "Walkability in Indian Cities - Clean Air Asia."

Jain, A. K., Murty, M. N \& Flynn, P. J. (1999). "Data clustering: a review." ACM computing surveys (CSUR) 31(3), pp. 264-323.

Jun, H. J \& Hur, M. (2015) "The Relationship between Walkability and Neighborhood Social Environment: The Importance of Physical and Perceived Walkability." Applied Geography 62, pp.115-124.

Kaiser, H. F. (1974) "An Index of Factorial Simplicity." Psychometrika 39, pp. 31-36. 
Kouser, K \& Sunita. (2013) "A comparative study of K Means Algorithm by Different Distance Measures." International Journal of Innovative Research in Computer and Communication Engineering, 1.

Litman, T. A. (2003) "Economic value of walkability." Transportation Research Record $10(1)$, pp. 3-11.

Litman, T. A. (2009) "Economic Value of Walkability." Transportation Research Record: Journal of the Transportation Research Board 1828(10), pp. 3-11.

Litman, T. (2004) "Evaluating Public Transit Benefits and Costs." Victoria Public Transit Institute.

Lo, R. H. (2009) "Walkability: What Is It?" Journal of Urbanism International Research on Placemaking and Urban Sustainability 2(2), pp.145-166.

Mccann, B. (2005) "Active Living Research: Designing for Active Recreation." San Diego: San Diego State University.

Manaugh, K \& El-Geneidy, A. (2011) "Validating walkability indices: How do different households respond to the walkability of their neighborhood?" Transportation Research Part D: Transport and Environment 16(4), pp. 309-315.

Ministry of Urban Development (MOUD). (2008) "Studies on traffic and transportation policies and strategies in urban areas in India." Final Report of Ministry of Urban Development, New Delhi, India.

Mohan, D., Tiwari, G \& Bhalla, K. S. (2015) "An analysis of road traffic fatalities in Delhi, India." Accident Analysis \& Prevention 17(1), pp. 33-45.

Newman, P \& Kenworthy, J. (1999) "Sustainability and cities: overcoming automobile dependence." Washington, DC: Island press.

Owen, N., Cerin, E., Leslie, E., Dutoit, L., Coffee, N., Frank, L. D., Bauman, A. E., Hugo, G., Saelens, B. E \& Sallis, J. F. (2007) "Neighborhood Walkability and the Walking Behavior of Australian Adults." American Journal of Preventive Medicine 33(5), pp. 387-395.

Pushkarev, B \& Zupan, J. M. (1971) "Pedestrian travel demand." Highway Research Record, 355.

Raparthi, K. (2014) "Assessing Smart-Growth Strategies in Indian Cities: Grounded Theory Approach to Planning Practice." Journal of Urban Planning and Development 141(4), pp. 1-10.

Rattan, A. Campese, A and Eden, C. (2012) "Modeling walkability." Arc. User, 30(3).

Rousseeuw, P. J. (1987) "Silhouette: a graphical aid to the interpretation and validation of cluster analysis." Journal of Computational and Applied Mathematics 20, pp. 5365.

Stanford, C. B. (2003) "Upright: The evolutionary key to becoming human." Boston: Houghton Mifflin, ISBN 978-0-618-30247-5.

Stevens, B. F. (1992) "Price Value Perceptions of Travellers." Journal of Travel Research 31(2), pp. 44-48.

Shelton, T. (2008) "Visualizing sustainability in urban conditions." WIT Transactions on Ecology and the Environment 113, pp. 253-262.

Smith, A. (2009) "Contribution of perceptions in analysis of walking behavior." Transportation Research Record: Journal of the Transportation Research Board 2140, pp. 128-136.

Whyte, W. H. (1980) "The social life of small urban spaces." Washington, DC: Conservation Foundation. 
European Transport $\backslash$ Trasporti Europei (2021) Issue 82, Paper n 1, ISSN 1825-3997

Weinberger, R \& Sweet, M. N. (2012) Integrating Walkability into Planning Practice. Transportation Research Record 2322(1), pp. 20-30.

Watkins, M. W. (2018) "Exploratory Factor Analysis: A Guide to Best Practice." Journal of Black Psychology 44(3), pp. 219-246.

Yong, A. G \& Pearce, S. (2013). "A Beginner's Guide to Factor Analysis: Focusing on Exploratory Factor Analysis." Tutorials in Quantitative Methods for Psychology 9(2), pp. 79-94.

Yusuf, A \& Waheed, A. (2015). "Measuring and Evaluating Urban Walkability through Walkability Indexes: A Case of Murree." European Transport-Transporti Europei (59). 